\title{
High definition video loggers provide new insights into behaviour, physiology, and the oceanic habitat of a marine predator, the yellow-eyed penguin
}

Thomas Mattern ${ }^{\text {Corresp., }}{ }^{1,2}{ }^{\text {, }}$ Michael D McPherson ${ }^{3}$, Ursula Ellenberg ${ }^{2,4}$, Yolanda van Heezik ${ }^{1}$, Philipp J Seddon ${ }^{1}$

1 Department of Zoology, University of Otago, Dunedin, Otago, New Zealand

2 Global Penguin Society, Puerto Madryn, Chubut, Argentina

3 CTNova Ltd., Leighton Buzzard, Bedfordshire, United Kingdom

4 Department of Ecology, Environment and Evolution, La Trobe University, Melbourne, Victoria, Australia

Corresponding Author: Thomas Mattern

Email address: t.mattern@eudyptes.net

Camera loggers are increasingly used to examine behavioural aspects of free-ranging animals. However, often video loggers are deployed with a focus on specific behavioural traits utilizing small cameras with a limited field of view, poor light performance and video quality. Yet rapid developments in consumer electronics provide new devices with much improved visual data allowing a wider scope for studies employing this novel methodology. We developed a camera logger that records full HD video through a wide-angle lens, providing high resolution footage with a greater field of view than other camera loggers. The main goal was to assess the suitability of this type of camera for the analysis of various aspects of the foraging ecology of a marine predator, the yellow-eyed penguin in New Zealand. Frame-by-frame analysis allowed accurate timing of prey pursuits and time spent over certain seafloor types. The recorded video footage showed that prey species were associated with certain seafloor types, revealed different predator evasion strategies by benthic fishes, and highlighted varying energetic consequences for penguins pursuing certain types of prey. Other aspects that could be analysed were the timing of breathing intervals between dives and observe exhalation events during prey pursuits, a previously undescribed behaviour. Screen overlays facilitated analysis of flipper angles and beat frequencies throughout various stages of the dive cycle. Flipper movement analysis confirmed decreasing effort during descent phases as the bird gained depth, and that ascent was principally passive. Breathing episodes between dives were short $(<1 \mathrm{~s})$ while the majority of the time was devoted to subsurface scanning with a submerged head. Video data recorded on free-ranging animals not only provide a wealth of information recorded from a single deployment but also necessitate new approaches with regards to analysis of visual data. Here, we demonstrate the diversity of information that can be 
gleaned from video logger data, if devices with high video resolution and wide field of view are utilized. 


\section{High definition video loggers provide new insights into}

\section{2 behaviour, physiology, and the oceanic habitat of a marine}

\section{3 predator, the yellow-eyed penguin}

4

5 Thomas Mattern ${ }^{1,2}$, Mike McPherson ${ }^{3}$, Ursula Ellenberg ${ }^{4,2}$, Yolanda van

6 Heezik $^{1}$, Philip J. Seddon ${ }^{1}$

$7 \quad{ }^{1}$ Department of Zoology, PO Box 56, University of Otago, Dunedin, NZ

$8{ }^{2}$ Global Penguin Society, Marcos Zar 2716, Puerto Madryn (9120), Chubut, Argentina.

$9{ }^{3}$ CTNova Ltd, Leighton Buzzard, Bedfordshire, England

$10{ }^{4}$ Department of Ecology, Environment and Evolution, La Trobe University, Melbourne, Australia

11 Corresponding author: Thomas Mattern ${ }^{1}$

12 Email address: t.mattern@eudyptes.net 


\section{Abstract}

14 Camera loggers are increasingly used to examine behavioural aspects of free-ranging animals.

15 However, often video loggers are deployed with a focus on specific behavioural traits utilizing small

16 cameras with a limited field of view, poor light performance and video quality. Yet rapid

17 developments in consumer electronics provide new devices with much improved visual data

18 allowing a wider scope for studies employing this novel methodology. We developed a camera logger that records full high-definition (HD) video through a wide-angle lens, providing high resolution footage with a greater field of view than other camera loggers. The main goal was to assess the suitability of this type of camera for the analysis of various aspects of the foraging ecology of a marine predator, the yellow-eyed penguin (Megadyptes antipodes) in New Zealand. Frame-by-frame analysis allowed accurate timing of prey pursuits and time spent over certain seafloor types. The recorded video footage showed that prey species were associated with certain seafloor types, revealed different predator evasion strategies by benthic fishes, and highlighted varying energetic consequences for penguins pursuing certain types of prey. Other aspects that could be analysed were the timing of breathing intervals between dives and observed exhalation events during prey pursuits, a previously undescribed behaviour. Screen overlays facilitated analysis of flipper angles and beat frequencies throughout various stages of the dive cycle. Flipper movement analysis confirmed decreasing effort during descent phases as the bird gained depth, and that ascent was principally passive. Breathing episodes between dives were short $(<1 \mathrm{~s})$ while the majority of the time was devoted to subsurface scanning with a submerged head. Video data recorded on free-ranging animals not only provide a wealth of information recorded from a single deployment but also necessitate new approaches with regards to analysis of visual data. Here, we demonstrate the diversity of information that can be gleaned from video logger data, if devices with high video resolution and wide field of view are utilized. 


\section{Introduction}

38 Examining the at-sea behaviour of marine animals has long been a challenging endeavour. Direct

39 visual observations of behaviour are almost impossible, especially when most of it happens under

40 the ocean's surface. In recent decades, advances in telemetry technologies and the emergence of

41 bio-logging hardware have provided the means to track marine animals and reveal their foraging

42 behaviour in great detail. Starting in the 1970s with rather crude location estimates and limited

43 data quality recorded by unwieldy devices that could only be used on large animals, advancements

44 in micro-electronics have resulted in ever smaller and more accurate loggers to pinpoint an

45 animal's position to within a few metres and record their diving depths with oceanography-grade

46 precision (Wilmers et al., 2015). New technologies such as accelerometers and gyroscopes further

47 refined methods to study marine habitat use (e.g. Noda et al. 2014). Yet, placing dive metrics into a

48 complex behavioural and environmental context can be difficult; ideally a reference framework

49 based on direct observations is used to match up dive metrics and actual behaviours (e.g. Moreau et

50 al. 2009; Volpov et al. 2016). So, the original dilemma of having to make direct observations of

51 marine animal behaviours still persists. Animal-borne video recorders offer the means to overcome

52 this problem.

53

54

55

56

57

58

59

In recent years animal-borne camera systems have made it possible to log in situ observations of behaviour from the animal's point of view (Moll et al., 2007). For example, deployment of lightweight video cameras on flying birds provided new perspectives on prey pursuit in falcons (Kane $\&$ Zamani, 2014) and revealed how albatrosses use the presence of killer whales to locate prey (Sakamoto et al., 2009). No other animal group has been more subject to deployment of video recording devices in recent years than marine animals. By overcoming the observational barrier at sea, video loggers are providing copious amounts of novel data that range from identification of feeding strategies (Ponganis et al., 2000; Takahashi et al., 2008) and previously unknown food 
61 sources (Thiebot et al., 2017), to social interactions such as group foraging (Sutton, Hoskins \&

62 Arnould, 2015) or kleptoparasitism (Handley \& Pistorius, 2015). Video data also offer the means to

63 calibrate other bio-logging data (Watanabe \& Takahashi, 2013; Gómez-Laich et al., 2015).

64 What most of these studies have in common is their focus on specific behavioural traits while

65 providing limited information about the environment the behaviours occurred in. This is

66 principally due to limitations of the video hardware used, which has to be small and light-weight so

67 as to not overly impede the study animal's movement capabilities (Ludynia et al., 2012) and hence

68 behaviour. As a result, video quality (i.e. image resolution and field of view/FOV) is sacrificed in

69 favour of smaller cameras (e.g. Watanabe \& Takahashi, 2013; Gómez-Laich et al., 2015; Thiebot et

70 al., 2016, 2017). However, with the rise in popularity of action cams on the consumer market, new

71 video devices have recently become available with high definition video capabilities and wide-angle

72 optics, suitable for deployment even on smaller marine animals such as penguins. This leap in

73 quality has significant implications for the study of marine animals as it not only allows more

74 accurate monitoring of a wide-range of aspects of behaviours such as specific pursuit strategies and

75 capture efficiency, as well as prey identification and interactions with other species, but also

76 provides new opportunities for the visual analysis of the environment the animals use. This is

77 particularly relevant in species that forage at the seafloor where video data can provide extensive

78 information about the benthic habitat (Watanuki et al., 2008).

79 The yellow-eyed penguin (Megadyptes antipodes) in New Zealand is known to be a benthic forager

80 (Mattern et al., 2007) that feeds primarily on demersal fish species (van Heezik \& Davis, 1990;

81 Moore et al., 1995). It has been suggested that this strategy might come at the expense of reduced

82 behavioural flexibility, with subsequent vulnerability to changes in the marine environment

83 (Mattern et al., 2007). In particular, degradation of seafloor ecosystems in the wake of commercial

84 bottom fisheries are suspected to influence yellow-eyed penguin foraging success and population

85 developments (Browne et al., 2011; Mattern et al., 2013). While the species' at-sea movement and 
86

87

diving behaviour have been subject to a number of studies in the past decades (Moore et al., 1995; Mattern et al., 2007, 2013), information about their benthic habitat is very limited.

To assess the extent to which penguin behaviour and foraging success correlate with the composition of the benthic habitat, we developed a camera logger that records full high-definition (HD) videos through wide-angle lenses. The main focus of our study was to assess the suitability of the device for the visual analysis of penguin prey pursuit behaviour and characteristics of the benthic ecosystem. However, the deployment revealed far more information than was anticipated. The video data provided novel insights into physiological aspects of the penguin's diving activities and allowed us to draw conclusions about prey capture techniques. In this paper, we summarise our findings, demonstrate analytical approaches to evaluate animal-borne video data, and highlight the multi-disciplinary potential of wide-angle, full HD video loggers.

\section{Materials and methods}

\section{Study site and species}

The yellow-eyed penguin, classified as "Endangered" by the IUCN Redlist (BirdLife International, 2016), is one of five penguin species endemic to the New Zealand region and occurs on the subAntarctic Auckland and Campbell Islands as well as the south-eastern coastlines of New Zealand's South Island and Stewart Island (Seddon, Ellenberg \& van Heezik, 2013). This study was carried out at the Boulder Beach complex, Otago Peninsula, South Island, New Zealand $\left(45.90^{\circ} \mathrm{S}, 170.56^{\circ} \mathrm{E}\right)$.

Penguins from this site have been subject to foraging studies that have suggested substantial impact of bottom trawling activities on the yellow-eyed penguins' at-sea movements (Ellenberg \& Mattern, 2012; Mattern et al., 2013). 


\section{Video logger \& deployment}

108 We developed a high-definition video logger (dimensions LxWxH, 89x41x21mm; weight: $78 \mathrm{~g}$ )

109 which is combined with a time-depth recorder (TDR, 31x12x11mm, 6.5g; AXY-depth, Technosmart

110 Ltd. Italy) and a GPS logger (modified, epoxy encased i-gotU, GT-120, Mobile Action Technology Inc.,

111 Taiwan, 31x22x11mm, $12 \mathrm{~g}$ ). The latter two devices were combined into a single unit by gluing the

112 AXY-depth to the longer side of the GPS device. Camera and logger combination were then attached

113 individually in line to the lower back of the penguin using adhesive tape (Wilson et al., 1997).

114 Additional drag of the devices was principally limited to the cameras frontal area (Bannasch,

115 Wilson \& Culik, 1994).

116 The camera logger consisted of a modified Mobius action-cam with a $130^{\circ}$ wide-angle lens

117 (www.mobius-actioncam.com). To achieve the smallest and lightest device possible, the camera

118 electronics, video sensor and lens were removed from the casing and the battery replaced with a

1191200 mAh Lithium Polymer battery to extend recording time. A small bespoke timer board was

120 developed to allow the camera to be fired at a pre-determined time. Connections were provided to

121 allow programming logger start time and also to access the camera's USB port for managing camera

122 setting, extracting the video data and recharging the battery. The board was isolated electrically to

123 prevent the contacts from shorting as sea-water is conductive. Activation of the interface was

124 achieved using a Hall-effect device. An Arduino-based interface was developed to allow the current

125 date/time and logger start time to be set. The camera was programmed to record video data at a

126 resolution of $1920 \times 1080$ pixels (1080p) at a frame rate of 30 frames per second. Video data were

127 recorded in H.264 MPEG4 format and stored on a 32GB MicroSD card. The camera was

128 programmed to start recording at 11 am the following day when it was assumed that the penguin

129 had completed its travel phase and arrived at its foraging destination. The camera operated from

130 the programmed start time until the battery fell below the minimum operating voltage of the 
131 camera (ca. 2-4 hours). The device was recovered when the penguin returned from its foraging trip;

132 data were then downloaded through the camera's USB interface.

133 Since the logger stores video data as a series of full frame images ('progressive scan'), it was

134 possible to conduct a frame-by-frame analysis to accurately time components of the bird's

135 behaviour - i.e. breathing intervals, flipper beat frequencies and amplitudes - as well as time spent

136 over certain benthic habitats. Video analysis was conducted in professional editing software (Adobe

137 Premiere Pro CS 6, Adobe Systems Inc., San Jose, CA, USA) which allows the quick and precise

138 backward and forward navigation of the video material using the keyboard ("scrubbing") and

139 provides the option to display frame number in the preview timer.

140 The video logger was deployed on a breeding male yellow-eyed penguin tending two chicks on 17

141 December 2015. Deployment occurred at the penguin's nest on the evening of 17 December. The

142 bird was removed from the nest and placed in a cloth bag to reduce stress. The instrumentation

143 procedure lasted around 20 minutes after which the penguin was released back on its nest. The

144 bird left on a single foraging trip on 18 December before the device was recovered on 19 December;

145 the penguin continued to breed normally after the deployment.

\section{Failure to record GPS data}

147 Upon device recovery it became apparent that the GPS logger did not record any data after the

148 camera had started operating. It has since become evident, that the Mobius action-cam generates

149 significant electromagnetic interference which prevented the GPS logger from functioning properly.

150 This can be rectified by wrapping the camera with electrical shielding tape; however, in our case

151 the lack of shielding resulted in failure to record GPS data. 


\section{Analysis of behaviours \& habitat}

153 For detailed analysis of behaviours, we randomly selected 12 dive cycles (dive cycle = beginning of

154 the surface period until the end of the following dive's ascent phase) from the 46 dive cycles

155 recorded (i.e. one fourth of all dives) independent from prevalent behaviours exhibited during

156 these dives. This was due to the labour-intensive frame-by-frame analysis necessary for several of

157 the behaviours. Future analyses are ideally conducted automatically using machine learning

158 algorithms to reduce analysis time and increase accuracy (e.g. Valletta et al., 2017).

159 Prey pursuits \& capture. We defined the beginning of a prey pursuit as the moment when the 160 penguin markedly accelerated while swimming along the seafloor; the end was reached when the 161 penguin decelerated again to its previous cruise speed (if no prey was caught), or when the prey 162 item was swallowed completely. Acceleration and deceleration were associated with temporary 163 blurring of the video footage due to irregular body movement, allowing for exact timing of prey 164 pursuits. Where possible, prey species were identified from frames providing a clear view of the 165 prey item.

\section{Benthic habitat}

167 For all dives, the benthic habitat was classified according to sediment type (fine sand, coarse sand 168 with shell fish fragments, gravel), sediment structure (flat, sediment ripples) and composition of 169 the epibenthic communities. For the latter, we used a presence/absence approach with easy-to170 identify epibenthic species brittlestars (Ophiuroidea), anthozoans (anemones and soft corals), and

171 horse mussels (Atrina zelandica), within a 30-frame time window. Figure 1 provides a photographic 172 overview of the different habitat characteristics used. Future deployments with a functional GPS

173 logger can be used for more elaborate analysis of the benthic habitat, e.g. the creation of

174 biodiversity indices. 
175 Beyond prey and habitat interactions, the video data offered the opportunities to analyse various

176 physiological aspects of the penguin's behaviour.

177 Flipper movements. During dives, flipper beat frequencies (beats per minute, BPM) were

178 determined by counting the number of frames required to complete one flipper beat cycle,

179 beginning the count when the flipper angle reached its maximum upward inclination and ending

180 with the frame prior to the subsequent maximum upward inclination. In the video editing software,

181 we overlaid a template indicating 10, 30, 50, 70 and 90-degree angles radiating from the base of the

182 flippers on the video data (https://vimeo.com/179414575). This allowed us to visually determine

183 maximum amplitude of each flipper beat to the nearest $5^{\circ}$.

184 Surface breathing \& underwater exhalation. We timed breathing events when the penguin was

185 at the surface following a dive. Noting frame numbers when the bird raised its head out of the water

186 before lowering below the surface again made it possible to determine the times the penguin was

187 able to respire (https://vimeo.com/179414575\#t=145). Additional observations of exhalations

188 during the dive were noted.

189 A selection of edited video clips demonstrating the various behaviours and habitat types described

190 above can be accessed via https://vimeo.com/album/4103142.

\section{Dive data analysis}

192 Dive data recorded by the TDR at $1 \mathrm{~s}$ intervals and depth resolution of $\sim 0.1 \mathrm{~m}$ were analysed

193 following methods described in detail in Mattern et al. (2007). Dives were classified as pelagic or

194 benthic dives using dive profile characteristics, where near horizontal bottom phases with little

195 vertical variance as well as consistent maximum dive depths on consecutive dives were used as

196 cues for diving along the seafloor. This approach was validated by recorded video data. The TDR

197 also recorded tri-axial accelerometer data which have yet to be analysed. 
198 Statistical analysis was carried out in R 3.4.2 (R Core Team, 2014). Correlations were examined as

199 linear models (Pearson's correlation). Comparisons were conducted as simple t-tests accounting for 200 unequal variances (Welch's t-Test, Ruxton, 2006).

\section{Permits}

202 This study was approved by the Animal Ethics Committee of the University of Otago (UOO AEC 203 69/15) and field experiments conducted under research permits issued by the New Zealand 204 Department of Conservation (45799-FAU).

\section{Results}

\section{Foraging trip length, diving events and video coverage}

207 The day following camera deployment, the penguin performed a 10.7 hour-long foraging trip. The 208 first dive event was recorded at 5:30 hrs and the last event concluded at 16:10 hrs. The bird performed 286 dives of which 159 dive profiles matched the criteria for benthic dives (Figure 2). Median dive depth reached during benthic dives was 54.4m (range: 4.8-62.1 m, n=159) whereas the

211 majority of pelagic dives occurred in the upper $10 \mathrm{~m}$ of the water column (median: 7.8m, range: 0.5 -

$21231.7 \mathrm{~m}, \mathrm{n}=127$ ); camera footage confirmed these to be principally travelling behaviour

213 (https://vimeo.com/179414642). For the first 31/2 hours of the foraging trip (05:30-09:00 hrs) the

214 bird performed mainly pelagic dives, indicating primarily travelling behaviour towards its main

215 foraging grounds; yellow-eyed penguins are known to exhibit high individual site fidelity with 216 regards to foraging locations (Moore, 1999; Mattern et al., 2007). Between 09:00 and 16:00 hrs the

217 bird principally devoted its time to benthic diving while shallow dives dominated the remaining 10 218 minutes of the foraging trip (Figure 2). 


\section{Video coverage \& quality}

220 The camera operated continuously from 11:00:22 hrs to 13:01:43 hrs. Due to frame loss

221 representing a mean 1.6 seconds of footage when video data were written to the file every 3

222 minutes, total length of the recorded footage amounted to 2 hours 8 seconds. Forty-six complete

223 dives were video recorded which corresponds to $16 \%$ of all dive events; of these 32 dives were

224 benthic dives. However, dives were longer during the middle of the day so that camera footage

225 covered $25 \%$ of the trip's cumulative dive time. The video quality proved to be significantly better

226 than that recorded with other animal-borne camera deployed on penguins to date

227 (https://vimeo.com/268905870). The light sensitivity of the camera was adequate to record clear 228 images at dive depths close to $70 \mathrm{~m}$ and, combined with the large field of view, facilitated detailed

229 frame-by-frame analysis.

230 Prey pursuits \& capture

231 A total of 20 prey pursuits were recorded at the seafloor (Figure 3). Fourteen of these resulted in

232 successful capture of either opalfish (Hemerocoetes monopterygius, 10 specimens) or blue cod

233 (Parapercis colias, 2 specimens); prey species could not be identified during two captures, but the

234 penguin's searching behaviour and ease of ingestion suggested these were opalfish and we include

235 them with opalfish captures below and in Figure 3. All of these prey pursuits occurred at the sea

236 floor with the penguin swimming very close to the bottom (https://vimeo.com/179414724).

237 During the camera operation time, the penguin spent 5.7 minutes on prey pursuit, which

238 corresponds to $19 \%$ of the total time the bird foraged along the seafloor (29.9 minutes) and $6 \%$ of

239 its total dive time (89.9 minutes). The penguin spent most of its active prey pursuit on opalfish

240 (total 3.8 minutes, 12 events), 0.7 minutes were used to capture blue cod (2 events), and 1.2

241 minutes of prey pursuit did not result in successful prey capture (Figure 3). 
242 Two main prey pursuit strategies became apparent that were associated with prey species. When

243 catching opalfish, the penguin would glide closely above the seafloor, sometimes briefly

244 accelerating before starting to hover over a certain spot while repeatedly pecking at the substrate

245 until the prey item was captured (https://vimeo.com/179414724). During encounters with blue

246 cod prolonged pursuits ensued during which fish zigzagged at a fast pace along the seafloor

247 (https://vimeo.com/179414724\#t=2m46s). In one instance the fish was caught as it appeared to

248 seek shelter at the base of a horse mussel protruding from the substrate

249 (https://vimeo.com/179414724\#t=2m55s). An unsuccessful prey pursuit of blue cod ended with

250 the fish escaping under what appeared to be a half-buried back plate of a dishwasher

251 (https://vimeo.com/179414777). A third blue cod encounter occurred just seconds after a

252 successful capture of an opalfish; it seems likely that the resulting prolonged bottom time and

253 oxygen-demanding prey pursuits drove the penguin to carry the fish to the surface at an almost

254 vertical angle as indicated sun disc's central position in the frame; the fish was ultimately dropped

255 at the surface (https://vimeo.com/179414724\#t=3m07s).

256 Benthic habitat

257 During the video logger's operating time, the penguin spent 29.9 minutes foraging along the

258 seafloor. The majority of the penguin's bottom time (90\%) was spent over coarse sand, whereas

259 time spent over fine sand (7\%) and gravel (0.9\%) was negligible (Figures $1 \& 3$ ). Two thirds of the

260 bottom time (65.9\%) was spent over sand ripples, the remaining time $(34.1 \%)$ the bird foraged

261 over flat ground. Brittle stars and anthozoans were present in most areas visited by the penguin

262 with the former being present in 22.5 mins (75\%) of the benthic video footage while the latter

263 occur for a total of 17.9 mins (60\%). Horse mussels were present for a total of 9.3 minutes (31\%) of

264 the bottom time. 
265 Prey encounters were associated with certain benthic habitat types. All prey encounters occurred

266 over coarse sand although the sediment structure differed depending on prey species. Opalfish

267 were principally encountered on sediment ripples (93.6\% of the total prey pursuit time,

268 https://vimeo.com/179414724), while flat bottom habitat played a more important role during

269 blue cod pursuits ( $52.8 \%$ of blue cod pursuit time, https://vimeo.com $/ 179414724 \# t=2 \mathrm{~m} 32 \mathrm{~s})$. With

270 regards to epibenthic characteristics, brittle stars and anemones were present during the majority

271 of the prey pursuit times for both fish species (Figure 3). However, horse mussels were present

272 only during blue cod pursuits (81.4\% of blue cod pursuit time).

\section{Flipper movements}

274 When descending to the sea floor the penguin propelled itself with fast, strong flipper strokes that

275 got progressively slower and less pronounced with time and, thus, increasing depth (Pearson

276 correlation - flipper amplitude: $R^{2}=0.69, F_{1,363}=791.8, \mathrm{p}<0.001, \mathrm{BPM}: R^{2}=0.13, F_{1,363}=55.2, \mathrm{p}<0.001$,

277 Figure 4a\&b; https://vimeo.com/179414575). In contrast, ascending was principally passive with

278 the penguin using its natural buoyancy to return to the surface, occasionally aided by a few strokes

279 in the early stages of the ascent, decreasing beat frequency (flipper amplitude: $R^{2}=0.01, F_{1,74}=0.49$,

$280 \mathrm{p}=0.49 ;$ BPM: $R^{2}=0.27, F_{1,76}=28.5, \mathrm{p}<0.001$, Figure 4c\&d) and no observable flipper movements

281 towards the end of the dive (https://vimeo.com/179414575\#t=1m49s). Despite differences in

282 flipper movement between the two transit phases of a dive, the vertical velocities recorded by the

283 TDR did not differ significantly (mean descent velocity: $1.45 \pm 0.28 \mathrm{~m} / \mathrm{s}$, mean ascent velocity:

$2841.36 \pm 0.57 \mathrm{~m} / \mathrm{s}, \mathrm{n}=159$ dives, Welch's t-test: $t_{232}=1.73, \mathrm{p}=0.09$ ).

285 During the bottom phase flipper amplitudes showed no correlation with relative bottom time

286 (flipper amplitude: $R^{2}=0.001, F_{1,479}=0.67, \mathrm{p}=0.42$ (Figure 4c), likely owing to the fact that bottom

287 phases consisted of a mix of searching behaviour and high-speed prey pursuit

288 (https://vimeo.com/179414575\#t=0m33s). While searching the penguin showed lower flipper 
289 beat frequencies $(133 \pm 48 \mathrm{BPM}, \mathrm{n}=809)$ paired with greater flipper amplitudes $\left(53^{\circ} \pm 14^{\circ}\right)$ when 290 compared to prey pursuit (BPM: $162 \pm 44, \mathrm{n}=113$, Welch's t-test: $t_{232}=-13.4, \mathrm{p}<0.001$; amplitude:

$29145^{\circ} \pm 7^{\circ}, t_{152}=6.4, \mathrm{p}<0.001$ ). Flipper beat frequency increased slightly but consistently towards the 292 end of the bottom phase (BPM: $R^{2}=0.02, F_{1,484}=8.2, \mathrm{p}=0.004$, Figure $4 \mathrm{~d}$ ), most likely as a result of the 293 penguin often starting its ascent back to the surface not long after successful prey captures 294 (https://vimeo.com/179414575\#t=1m45s).

\section{Surface breathing \& underwater exhalation}

296 Frame counts of the video footage during 12 random selected surface periods between dives

297 showed that the penguin lifted its head out of the water to breathe for only brief moments (average 298 duration: $0.77 \pm 0.22 \mathrm{~s}, \mathrm{n}=193$ ); for the majority of the time at the surface the bird kept its head 299 under water $(1.53 \pm 1.19 \mathrm{~s}, \mathrm{n}=182)(\mathrm{https}: / /$ vimeo.com/179414575\#t=2m25s). Duration of 300 breathing intervals increased with ongoing duration of the surface period (Pearson correlation: $\left.301 \rho=0.45, F_{1,191}=47.4, \mathrm{p}<0.001\right)$ indicating increased respiration activity in preparation for the next 302 dive (Figure 5).

303 During the dive, exhalation regularly occurred at the onset of phases with increased acceleration 304 (i.e. prey pursuit). Such exhalations were brief but performed with substantial force; air was jetted 305 from the nostrils as a fine gas spurt (https://vimeo.com/179418254). During the passive phase of 306 the ascent, the penguin frequently exhaled as indicated be a stream of large bubbles released from 307 the nostrils. The bird released substantial amounts of air on the last few meters immediately prior 308 to reaching the surface (https://vimeo.com/179414575\#t=2m18s). While some of this air may 309 have been released from the plumage (c.f. Davenport et al. 2011) bubbles seem principally to 310 originate from the frontal head region; there was no visible major gas release from the penguin's 311 back region. 


\section{Discussion}

313 The high-quality video footage provided a substantial amount of new insights into the foraging

314 behaviour of yellow-eyed penguins and their benthic habitat. While it is impossible to draw far-

315 ranging conclusions from only a single deployment, it nevertheless highlights that high-definition

316 cameras provide a new tool facilitating the examination of various aspects of the foraging ecology of

317 marine predators through direct observation. It can be particularly useful to verify and calibrate

318 behaviours measured with other types of devices such as TDR and accelerometers.

\section{Device effects}

320 Attaching external recording devices to diving animals always comes at the cost of compromising

321 their streamlined body shape (e.g. Ludynia et al., 2012), a problem that can be mitigated via device

322 shape, size and attachment position (Bannasch, Wilson \& Culik, 1994). At the surface there were no

323 indications that the penguin was negatively affected by the device; the bird did not exhibit

324 balancing problems which externally attached devices can cause in smaller species (Chiaradia et al.,

325 2005), nor did it peck at the device frequently which suggests aberrant behaviour (Wilson \&

326 Wilson, 1989). Moreover, the number of successful prey captures further suggests that the bird's

327 foraging capabilities were not drastically affected by the video logger. With the exception of two

328 unsuccessful blue cod encounters, all events classified as prey pursuit were merely accelerations

329 that did not end in any obvious prey encounter. The bird was one of the few breeders that raised

330 two chicks to fledging in an otherwise poor breeding season.

\section{Predator-prey interactions \& prey species importance}

332 In line with previous descriptions of yellow-eyed penguins as primarily benthic foragers (Mattern 333 et al., 2007), the penguin's prey pursuit and captures recorded during the camera operation indeed

334 all occurred at the sea floor. Swimming very close to the seafloor could serve several purposes. It

335 could be a strategy to flush out benthic prey that blends in with the substrate, but it could also 
336 mean the penguin has a greater chance to see its prey from the side, and thus reduce the effect of

337 prey camouflage. Opalfish, for example, are very well camouflaged and very difficult to make out

338 from above (Roberts, Stewart \& Struthers, 2015). This species seems to principally rely on its

339 camouflage as means of predator avoidance since none of the opalfish captures involved a chase. In

340 contrast, during both successful blue cod encounters, extended high-speed chases ensued before

341 the fish was ultimately captured. Blue cod and opalfish differ significantly in their anatomy with the

342 small, slender opalfish presumably lacking the physical prowess for prolonged swimming when

343 compared to muscular blue cod (Roberts, Stewart \& Struthers, 2015). When facing an air breathing

344 predator, the latter strategy is likely advantageous as the predator's increased energy requirements

345 for pursuit make escape a more likely outcome for the prey. The penguin's hasty ascent and

346 subsequent failure to consume a blue cod it captured after a 22-second-long chase demonstrates

347 the efficacy of this evasion strategy.

348 Both opalfish and blue cod have previously been found to be among the most important prey items

349 in the yellow-eyed penguin's diet (van Heezik, 1990a; Moore \& Wakelin, 1997). While both fish

350 species have comparable energetic values ( $20 \mathrm{~kJ} \mathrm{~g}^{-1}$, Browne et al., 2011), the body mass of

351 opalfish is considerably lower when compared to blue cod (van Heezik, 1990b,a). It is possible that

352 the energy gain from catching blue cod justifies the expenditure to catch it, while the easier-to-catch 353 opalfish might need to be caught in larger quantities. However, recent studies suggest that blue cod

354 might be suboptimal prey for chick-rearing yellow-eyed penguins due to their size (Browne et al.,

355 2011; Mattern et al., 2013) so that the penguin's ability to locate prey such as opalfish might be a

356 decisive factor with regards to reproductive success.

\section{Benthic environment}

358 Judging from the total time the bird spent over a benthic environment dominated by coarse sand 359 and sediment ripples (65.9\% of total bottom time) as well as almost exclusive encounters of 
360 opalfish over such habitat (Figures $1 \& 3$ ), it can be assumed that the penguin focussed principally

361 on this species. Blue cod encounters were associated with the presence of horse mussels. These

362 large bivalves protrude from the seafloor and provide hard substrate for other epibenthic taxa,

363 thereby increasing local benthic biodiversity (Cummings et al., 1998). Benthic habitat with

364 increased benthic biodiversity is generally more attractive to a variety of benthic fish species, most

365 likely due to enhanced feeding conditions (Cranfield et al., 2001). Our video data also suggests that

366 the fish use the bivalves and associated cavities as shelter to avoid capture

367 (https://vimeo.com/179414777).

368 The majority of prey pursuits occurred in areas that featured anthozoans, principally sea anemones

369 (Figures 1 \& 3). Anemones are known to play an important role as refugia and feeding habitats for

370 small fish (Elliott, 1992) and could therefore be another indicator for locally increased biodiversity.

371 Brittle stars on the other hand, although equally abundant, seemed to be of lesser relevance with

372 regards to prey encounters. So, it appears that examining the composition of the benthic habitat

373 alone might enable assessment of which prey types penguins are foraging for, though more data are

374 required before conclusions can be drawn. However, this already hints at the potential for wide-

375 ranging habitat analysis of at-sea movements in benthic predators, provided that spatial

376 distribution of the different benthic habitats can be obtained. While in our specific case, no such

377 habitat maps exist, planned further deployments of video loggers are expected to provide the

378 necessary environmental information.

379 Deploying video loggers on penguins could enable detailed mapping of the benthic habitat within

380 the species' home ranges. Yellow-eyed penguins are known to have preferred individual foraging

381 areas often with little overlap between birds (Moore, 1999). Moreover, the birds tend to often dive

382 along the seafloor when swimming towards their foraging grounds (Mattern et al. 2007) so that

383 camera logger data in combination with GPS information can be used to establish spatial

384 biodiversity indices and benthic habitat maps. 
385 The outer ranges of the marine habitat of yellow-eyed penguins from the Otago Peninsula is subject

386 to bottom fisheries which have a profound effect on benthic ecosystems (e.g. Hinz et al., 2009;

387 Queirós et al., 2006; Schratzberger and Jennings, 2002). Yellow-eyed penguins have been found to

388 forage in the wake of trawl fisheries, potentially to the detriment of their reproductive success

389 (Mattern et al., 2013). Changes in sediment structure and epibenthic biodiversity as a result of

390 bottom trawl disturbance likely negatively affect the penguins' foraging success (Browne et al.,

391 2011). Camera loggers can help to determine how much of the penguins' foraging habitat has been

392 compromised by fishing activities and what the consequences are for this species' foraging

393 behaviour and success.

394 Beyond investigations of behaviour in a wider environmental context, our study also shows the 395 potential application of camera loggers for the investigation of physiological aspects of marine 396 animals.

397 Flipper movements

398 Our observations of flipper movements, i.e. strong flipper movements at the beginning of a dive that 399 decrease with depth, and cessation of flipper movements during ascent, align with findings 400 reported in other penguins. Using accelerometers, Sato et al. (2002) found that King penguins 401 showed vigorous flipper beating at the beginning of a dive to counter positive buoyancy. With 402 increasing depth, air volume in the penguin's body becomes compressed, reducing its buoyancy so 403 that fewer flipper beats are required. That this also applies to flipper amplitude (Figure 4) was not 404 detectable by using body acceleration as the only measure. A more elaborate system of sensors and 405 magnets attached to flippers was used on Magellanic penguins which allowed the recording of both 406 flipper amplitudes and beat frequencies (Wilson \& Liebsch, 2003). However, the system is known to 407 be prone to failure, rendering the use of back-mounted wide-angle cameras a much more reliable 408 alternative. Flipper beat frequencies and amplitudes are directly related to energy expenditure 
409 (Kooyman \& Ponganis, 1998; Sato et al., 2011). They provide the means for the quantification of 410 energy budgets (Wilson \& Liebsch, 2003) and subsequently can be used to assess individual fitness

411 in relation to foraging success and subsequent reproductive performance (Kooyman \& Ponganis, 412 1998).

413 We provide evidence that the ascent phase in penguins is largely passive, as has been suggested 414 using both accelerometers and magnets (Sato et al., 2002; Wilson \& Liebsch, 2003). Sato et al. 415 (2002) concluded that during ascent penguins benefit from expanding air volume in their body 416 which increases their buoyancy as they get closer to the surface. Penguins also actively slow down 417 their ascent and it was argued that this could be achieved by increasing the attack angles of their 418 flippers to increase drag (Sato et al., 2002). Judging from body movements apparent in the video 419 data during the ascent phases we suggest that the yellow-eyed penguin indeed adjusted flipper 420 attack angles while ascending, although this seems to be more for steering. Based on the video 421 footage it appears that the bird uses controlled exhalation towards the end of the ascent to control 422 speed (https://vimeo.com/179414575\#t=2m18s).

\section{Respiration}

424 The video data provide new insights into the respiration of yellow-eyed penguins. To date it was 425 unclear whether penguins exhale regularly while diving. Various studies estimated diving air 426 volume via a penguin's buoyancy calculated from its ascent speeds at the ends of dives (Sato et al., $4272002,2011)$. However, the accuracy of this approach is compromised if the penguins were to exhale 428 prior to their final ascent (Ponganis, St Leger \& Scadeng, 2015). The video data clearly showed that 429 the penguin generally exhaled when accelerating during prey pursuit so that models estimating 430 diving air volume via the proxy buoyancy must take acceleration into account. The fact that the 431 penguin exhaled when accelerating probably serves the purpose of reducing blood $\mathrm{CO}_{2}$ and 432 mobilizing $\mathrm{O}_{2}$ from oxygen stores for prey pursuit. Such pursuits must be costly in terms of oxygen 
433 consumption as is evident from the observed consecutive prey encounters during one single dive,

434 which resulted in the penguin letting go of the second fish after a rapid ascent to the surface

435 (https://vimeo.com/179414724\#t=3m07s). Unlike seals that have been found to exhale when

436 ascending from deep dives, most likely to reduce the drop in blood oxygen (Hooker et al., 2005), the

437 penguin principally exhaled during the second half of the ascent possibly indicating adjustment of

438 buoyancy and ascent speed (but see also Davenport et al. 2011). Reoxygination during the surface

439 period in penguins is highly optimized (Wilson et al., 2003). Inhalation events at the surface are

440 brief so that the bird can frequently lower its head into the water, presumably in an effort to look

441 out for potential predators (e.g. sharks, sea lions; Seddon et al., 2013). Extensive exhalation prior to

442 resurfacing also prevents pulmonary barotrauma and facilitates immediate inhalation once back at 443 the surface.

\section{Conclusions}

445 The deployment of a full HD video logger on a yellow-eyed penguin resulted in a versatile visual 446 data set that provided a variety of information well beyond what was initially intended. Enhanced 447 video quality allows detailed analysis of the benthic environment as well as prey encounter rates 448 and prey composition. In combination with GPS data, the potential for a comprehensive survey of 449 benthic ecosystems is substantial highlighting the multi-disciplinary potential of such data.

450 A large field of view achieved through wide-angle lenses furthermore allows detailed analysis of 451 flipper movements, which to date could only be achieved through elaborate modelling of 452 accelerometer data (Sato et al., 2002, 2011) or use of complicated magnetic logger setups (Wilson \& 453 Liebsch, 2003). Neither of these setups provided information about exhalation, which appears to 454 play a much more important role during diving than previously thought. When comparing video 455 data recorded here with videos from previously published studies (e.g. Watanabe and Takahashi, 456 2013, https://vimeo.com/268905870) it becomes clear that greater visual fidelity of full HD 
457 cameras comes along with a much wider range of quantifiable data. This creates a new opportunity

458 for a more holistic approach to study the diving behaviour of marine animals that integrates

459 behaviour, physiology and their environment.

460 Depending on which behaviours are quantified, the manual analysis of video data can be quite time461 consuming. For example, flipper beats and angles require a frame-by-frame analysis; an average 462 dive duration of 3 minutes translated to 5400 frames per dive. However, the higher the resolution 463 and quality of the video footage, the greater the potential to develop machine learning algorithms

464 (such as Google Cloud Video Intelligence; https://cloud.google.com/video-intelligence/) that may

465 be used to automate the analysis process. For more basic analyses such as prey composition and 466 encounter rates, but also determination of environmental parameters, there already exist software 467 solutions that offer an enhanced workflow, for example the video annotation software BORIS 468 (http://www.boris.unito.it/).

469 Obviously, there are still limitations to the use of camera loggers. Restrictions arise from the battery 470 life as well as the memory to store high definition video data. In our case, 15 minutes of footage 471 resulted in video file sizes of 1.5 gigabytes. Moreover, the deployment with the camera set-up we 472 used requires a certain amount of predictability, particularly knowledge about how soon after 473 departure the bird is likely to engage in behaviours that are of interest (e.g. prey pursuit). For all 474 these reasons, the technology currently available is best suited for short-term deployments on 475 central place foragers. Although video data recorded on animals performing long-term foraging 476 trips (e.g. Magellanic penguins, Boersma \& Rebstock, 2009) might still deliver valuable data, this 477 has to be weighed against the fact that external devices inevitably have an effect on the animal's 478 foraging ability (Bannasch, Wilson \& Culik, 1994; Ludynia et al., 2012). This could be alleviated by 479 incorporating further mechanisms to control camera recording (e.g. duty-cycling of recording 480 function, pressure control). While the use of animal-borne cameras for scientific research is still in 
481 its early day, the enormous potential of this technology will doubtlessly result in devices

482 incorporating more elaborate functionality in the future.

\section{Acknowledgments}

484 We would like to thank Horst Mattern, Melanie Young and Jim Watts for help in the field, and Leon 485 Berard for first preliminary evaluation of the video data. Special thanks are due to Bruce McKinlay

486 (Department of Conservation) for supporting this project and facilitating the permitting process of 487 a novel bio-logging method. 


\section{References}

489 Bannasch R., Wilson RP., Culik BM. 1994. Hydrodynamic aspects of design and attachment of a 490 back-mounted device in penguins. Journal of Experimental Biology 194:83-96.

491 BirdLife International. 2016. Megadyptes antipodes. The IUCN Red List of Threatened Species

492

493 2012:e.T22697800A93640603. DOI: 10.2305/IUCN.UK.20163.RLTS.T22697800A93640603.en.

Boersma PD., Rebstock GA. 2009. Foraging distance affects reproductive success in Magellanic penguins. Marine Ecology Progress Series 375:263-275. DOI: 10.3354/meps07753.

Browne T., Lalas C., Mattern T., Van Heezik Y. 2011. Chick starvation in yellow-eyed penguins: Evidence for poor diet quality and selective provisioning of chicks from conventional diet analysis and stable isotopes. Austral Ecology 36:99-108. DOI: 10.1111/j.14429993.2010.02125.x.

Chiaradia A., Ropert-coudert Y., Healy M., Knott N. 2005. Finding the balance : the effect of the position of external devices on little penguins. Polar Bioscience 18:46-53.

Cranfield HJ., Carbines G., Michael KP., Dunn A., Stotter DR., Smith DJ. 2001. Promising signs of regeneration of blue cod and oyster habitat changed by dredging in Foveaux Strait, southern New Zealand. New Zealand Journal of Marine and Freshwater Research 35:897-908. DOI: 10.1080/00288330.2001.9517052.

Cummings VJ., Thrush SF., Hewitt JE., Turner SJ. 1998. The influence of the pinnid bivalve Atrina zelandica (Gray) on benthic macroinvertebrate communities in soft-sediment habitats. Journal of Experimental Marine Biology and Ecology 228:227-240. DOI: 10.1016/S00220981(98)00028-8. 
510 Davenport J., Hughes RN., Shorten M., Larsen PS. 2011. Drag reduction by air release promotes fast

511 ascent in jumping emperor penguins-a novel hypothesis. Marine Ecology Progress Series

$512 \quad$ 430:171-182. DOI: 10.3354/meps08868.

513 Ellenberg U., Mattern T. 2012. Yellow-eyed penguin - review of population information. Report

514 POP2011-08. Conservation Services Programme, Department of Conservation. Wellington,

$515 \quad$ New Zealand. DOI: 10.13140/RG.2.2.21606.83523.

516 Elliott J. 1992. The role of sea anemones as refuges and feeding habitats for the temperate fish

517 Oxylebius pictus. Environmental Biology of Fishes 35:381-400. DOI: 10.1007/BF00004991.

518 Gómez-Laich A., Yoda K., Zavalaga C., Quintana F. 2015. Selfies of Imperial Cormorants

519 (Phalacrocorax atriceps): What Is Happening Underwater? PLOS ONE 10:1-18. DOI:

$520 \quad$ 10.1371/journal.pone.0136980.

521 Handley JM., Pistorius P. 2015. Kleptoparasitism in foraging gentoo penguins Pygoscelis papua.

522 Polar Biology 39:391-395. DOI: 10.1007/s00300-015-1772-2.

523 van Heezik Y. 1990a. Seasonal, geographical, and age-related variations in the diet of the Yellow-

524 eyed Penguin (Megadyptes antipodes). New Zealand Journal of Zoology 17:201-212.

525

526

527

528

529

530

van Heezik Y. 1990b. Diets of yellow-eyed, Fiordland crested, and little blue penguins breeding sympatrically on Codfish Island, New Zealand. New Zealand Journal of Zoology 17:543-548.

van Heezik Y., Davis LS. 1990. Effects of food variability on growth rates, fledging sizes and reproductive success in the Yellow-eyed Penguin Megadyptes antipodes. Ibis 132:354-365.

Hinz H., Prieto V., Kaiser MJ. 2009. Trawl disturbance on benthic communities: Chronic effects and experimental predictions. Ecological Applications 19:761-773. DOI: 10.1890/08-0351.1.

531 Hooker SK., Miller PJO., Johnson MP., Cox OP., Boyd IL. 2005. Ascent exhalations of Antarctic fur 
532

533

534

535

536

537

538

539

540

541

542

543

544

545

546

547

548

549

550

551

552

553

554

seals: a behavioural adaptation for breath-hold diving? Proceedings of the Royal Society B: Biological Sciences 272:355-363. DOI: 10.1098/rspb.2004.2964.

Kane SA., Zamani M. 2014. Falcons pursue prey using visual motion cues: new perspectives from animal-borne cameras. Journal of Experimental Biology 217:225-234. DOI: 10.1242/jeb.092403.

Kooyman GL., Ponganis PJ. 1998. The physiological basis of diving to depth: birds and mammals. Annual review of physiology 60:19-32. DOI: 10.1146/annurev.physiol.60.1.19.

Ludynia K., Dehnhard N., Poisbleau M., Demongin L., Masello JF., Quillfeldt P. 2012. Evaluating the Impact of Handling and Logger Attachment on Foraging Parameters and Physiology in Southern Rockhopper Penguins. PLOS ONE 7:e50429. DOI: 10.1371/journal.pone.0050429.

Mattern T., Ellenberg U., Houston DM., Davis LS. 2007. Consistent foraging routes and benthic foraging behaviour in yellow-eyed penguins. Marine Ecology Progress Series 343:295-306. DOI: $10.3354 / \operatorname{meps} 06954$.

Mattern T., Ellenberg U., Houston DM., Lamare M., Davis LS., Van Heezik Y., Seddon PJ. 2013. Straight line foraging in yellow-eyed penguins: new insights into cascading fisheries effects and orientation capabilities of marine predators. PLOS ONE 8:e84381. DOI: 10.1371/journal.pone.0084381.

Moll RJ., Millspaugh JJ., Beringer J., Sartwell J., He Z. 2007. A new 'view' of ecology and conservation through animal-borne video systems. Trends in Ecology \& Evolution 22:660-668. DOI: 10.1016/j.tree.2007.09.007.

Moore PJ. 1999. Foraging range of the Yellow-eyed penguin Megadyptes antipodes. Marine Ornithology 27:49-58.

Moore PJ., Wakelin MD. 1997. Diet of the Yellow-eyed penguin Megadyptes antipodes, South Island, 
556

557

558

559

560

561

562

563

564

565

566

567

568

569

570

571

572

573

574

575

576

577

Moore PJ., Wakelin MD., Douglas ME., McKinlay B., Nelson D., Murphy B. 1995. Yellow-eyed penguin foraging study, south-eastern New Zealand, 1991-1993. Wellington, N.Z.: Department of Conservation. Available at http://www.doc.govt.nz/Documents/science-andtechnical/sr83a.pdf.

Moreau M., Siebert S., Buerkert A., Schlecht E. 2009. Use of a tri-axial accelerometer for automated recording and classification of goats' grazing behaviour. Applied Animal Behaviour Science 119:158-170. DOI: 10.1016/j.applanim.2009.04.008.

Noda T., Kawabata Y., Arai N., Mitamura H., Watanabe S. 2014. Animal-mounted gyroscope/accelerometer/magnetometer: in situ measurement of the movement performance of fast-start behaviour in fish. Journal of Experimental Marine Biology and Ecology 451. DOI: 10.1016/j.jembe.2013.10.031.

Ponganis PJ., Van Dam RP., Marshall G., Knower T., Levenson DH. 2000. Sub-ice foraging behavior of emperor penguins. Journal of Experimental Biology 203:3275-3278.

Ponganis PJ., St Leger J., Scadeng M. 2015. Penguin lungs and air sacs: implications for baroprotection, oxygen stores and buoyancy. Journal of Experimental Biology 218:720-730. DOI: $10.1242 /$ jeb.113647.

Queirós AM., Hiddink JG., Kaiser MJ., Hinz H. 2006. Effects of chronic bottom trawling disturbance on benthic biomass, production and size spectra in different habitats. Journal of Experimental Marine Biology and Ecology 335:91-103. DOI: 10.1016/j.jembe.2006.03.001.

R Core Team. 2014. R: A Language and Environment for Statistical Computing.

Roberts CD., Stewart AL., Struthers CD. 2015. The Fishes of New Zealand. Wellington, New Zealand: Te Papa Press. 
578 Ruxton GD. 2006. The unequal variance t-test is an underused alternative to Student's t-test and the 579 Mann-Whitney U test. Behavioral Ecology 17:688-690. DOI: 10.1093/beheco/ark016.

580 Sakamoto KQ., Takahashi A., Iwata T., Trathan PN. 2009. From the Eye of the Albatrosses: A Bird581 Borne Camera Shows an Association between Albatrosses and a Killer Whale in the Southern 582 Ocean. PLOS ONE 4:e7322. DOI: 10.1371/journal.pone.0007322.

584

585

586

587

588

589

590

591

592

593

594

595

596

597

598

599

600

Sato K., Naito Y., Kato A., Niizuma Y., Watanuki Y., Charrassin JB., Bost C-A., Handrich Y., Le Maho Y. 2002. Buoyancy and maximal diving depth in penguins. Journal of Experimental Biology 205:1189-1197.

Sato K., Shiomi K., Marshall G., Kooyman GL., Ponganis PJ. 2011. Stroke rates and diving air volumes of emperor penguins: implications for dive performance. Journal of Experimental Biology 214:2854-2863. DOI: 10.1242/jeb.055723.

Schratzberger M., Jennings S. 2002. Impacts of chronic trawling disturbance on meiofaunal communities. Marine Biology 141:991-1000. DOI: 10.1007/s00227-002-0895-5.

Seddon PJ., Ellenberg U., van Heezik Y. 2013. Yellow-eyed penguin (Megadyptes antipodes). In: Garcia Borboroglu P, Boersma PD eds. Penguins: Natural History and Conservation. Seattle \& London: University of Washington Press, 91-110.

Sutton GJ., Hoskins AJ., Arnould JPY. 2015. Benefits of Group Foraging Depend on Prey Type in a Small Marine Predator, the Little Penguin. PLOS ONE 10:e0144297. DOI: 10.1371/journal.pone.0144297.

Takahashi A., Kokubun N., Mori Y., Shin H-C. 2008. Krill-feeding behaviour of gentoo penguins as shown by animal-borne camera loggers. Polar Biology 31:1291-1294.

Thiebot J-B., Arnould JPY., Gómez-Laich A., Ito K., Kato A., Mattern T., Mitamura H., Noda T., Poupart T., Quintana F., Raclot T., Ropert-Coudert Y., Sala JE., Seddon PJ., Sutton GJ., Yoda K., Takahashi 
601

602

603

604

605

A. 2017. Jellyfish and other gelata as food for four penguin species - insights from predatorborne videos. Frontiers in Ecology and the Environment 15:437-441. DOI: 10.1002/fee.1529.

Thiebot J-B., Ito K., Raclot T., Poupart T., Kato A., Ropert-Coudert Y., Takahashi A. 2016. On the significance of Antarctic jellyfish as food for Adélie penguins, as revealed by video loggers. Marine Biology 163:1-8. DOI: 10.1007/s00227-016-2890-2.

Valletta JJ., Torney C., Kings M., Thornton A., Madden J. 2017. Applications of machine learning in animal behaviour studies. Animal Behaviour 124:203-220. DOI: 10.1016/j.anbehav.2016.12.005.

Volpov BL., Rosen DAS., Hoskins AJ., Lourie HJ., Dorville N., Baylis AMM., Wheatley KE., Marshall G., Abernathy K., Semmens J., Hindell MA., Arnould JPY. 2016. Dive characteristics can predict foraging success in Australian fur seals (Arctocephalus pusillus doriferus) as validated by animal-borne video. Biology Open 5:262 LP-271.

Watanabe YY., Takahashi A. 2013. Linking animal-borne video to accelerometers reveals prey capture variability. Proceedings of the National Academy of Sciences 110:2199-2204. DOI: $10.1073 /$ pnas. 1216244110.

Watanuki Y., Daunt F., Takahashi A., Newell M., Wanless S., Sato K., Miyazaki N. 2008. Microhabitat use and prey capture of a bottom-feeding top predator, the European shag, shown by camera loggers. Marine Ecology Progress Series 356:283-293. DOI: 10.3354/meps07266.

Wilmers CC., Nickel B., Bryce CM., Smith JA., Wheat RE., Yovovich V. 2015. The golden age of biologging: how animal-borne sensors are advancing the frontiers of ecology. Ecology 96:17411753. DOI: $10.1890 / 14-1401.1$.

Wilson R., Liebsch N. 2003. Up-beat motion in swinging limbs: new insights into assessing movement in free-living aquatic vertebrates. Marine Biology 142:537-547. DOI: 
$624 \quad 10.1007 / \mathrm{s} 00227-002-0964-9$.

625 Wilson RP., Pütz K., Peters G., Culik BM., Scolaro JA., Charrassin J-B., Ropert-Coudert Y. 1997. Long-

626 term attachment of transmitting and recording devices to penguins and other seabirds.

$627 \quad 25: 101-106$.

628 Wilson RP., Simeone A., Luna-Jorquera G., Steinfurth A., Jackson S., Fahlman A. 2003. Patterns of 629 respiration in diving penguins: is the last gasp an inspired tactic? Journal of Experimental 630 Biology 206:1751-1763. DOI: 10.1242/jeb.00341.

631 Wilson RP., Wilson MT. 1989. A peck activity record for birds fitted with devices. Journal of Field 632 Ornithology 60:104-108.

633 


\section{Figure 1}

Types of benthic habitat utilized by a yellow-eyed penguin fitted with wide-angle, full HD camera logger.

(A) Flat gravel sediment with a diverse epibenthic community of horse mussels, sponges, ascidians and anemones; a habitat preferred by blue cod. (B) Coarse sand with pronounced ripples, typical habitat where opalfish were caught. (C) Flat gravel sediment with almost no sessile epibenthos; the presence of scavenging brittle stars indicates bottom fishing disturbance. (D) Flat, fine sand habitat with horse mussels and few brittle stars. The latter two habitats were also frequented by blue cod.

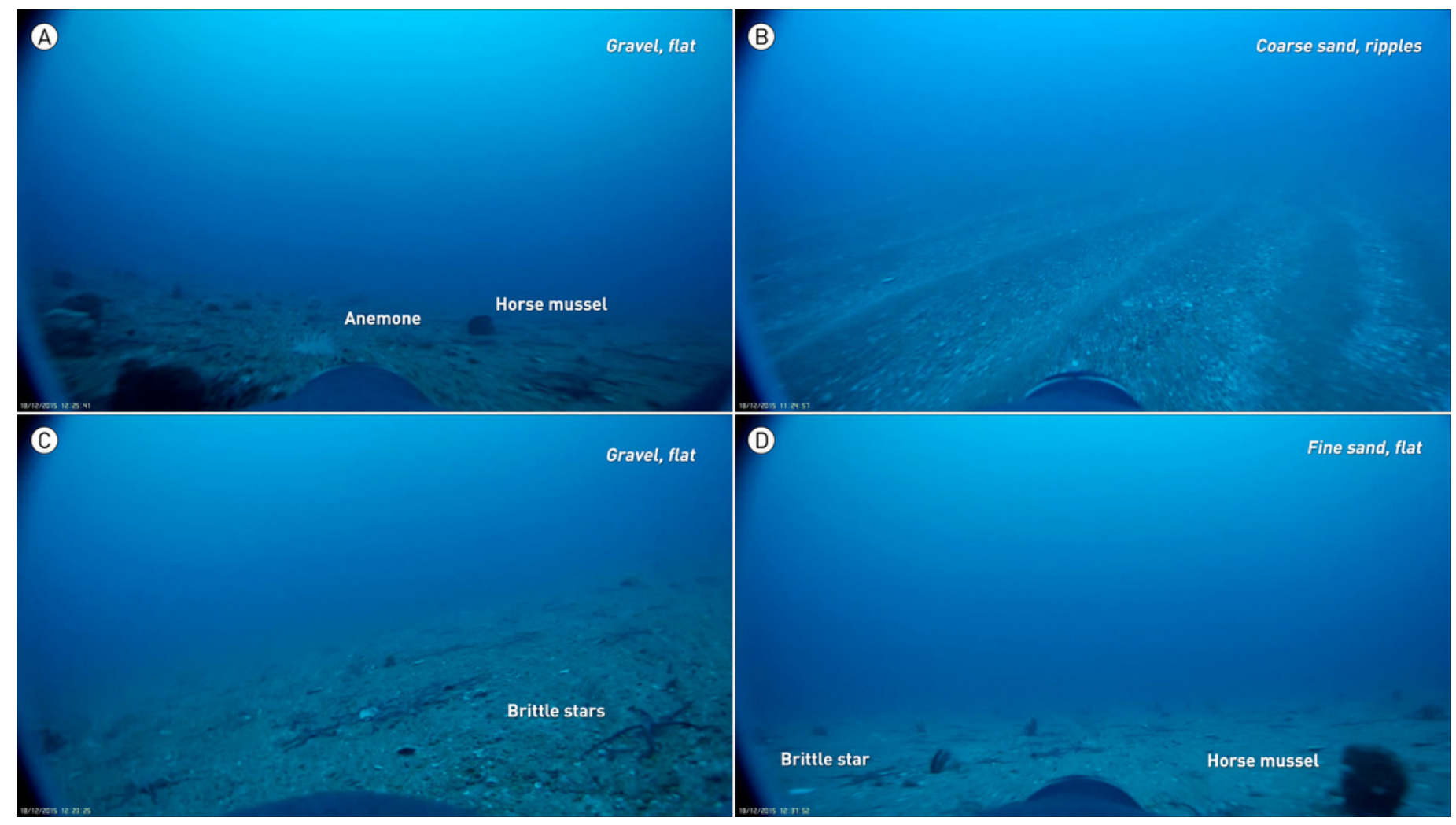




\section{Figure 2}

Proportion of benthic and pelagic dives throughout the yellow-eyed penguin's foraging trip while fitted with a camera logger.

Numbers at the top end of bars indicate number of dives performed during the corresponding hour. Red box indicates the hours during which continuous camera footage was recorded.

Benthic dives $\quad$ Pelagic dives

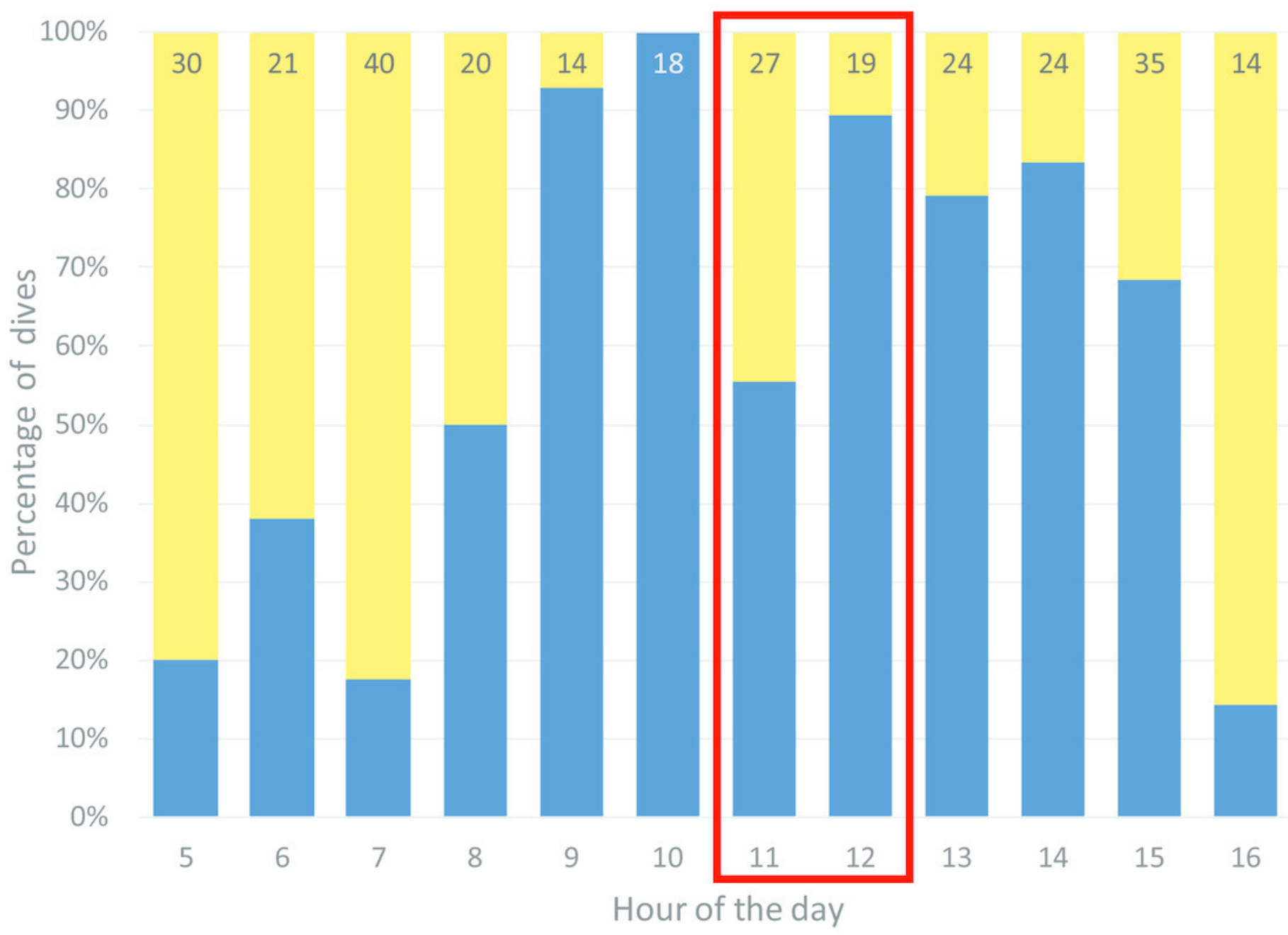




\section{Figure 3}

Timeline of a yellow-eyed penguin's prey pursuit events in relation to benthic features, i.e. composition of epibenthic community, sediment type and structure.

The $x$-axis indicates the cumulative time the penguin spent at the seafloor (29.9 minutes) during the 2 hours of camera operation. The top three rows of bars indicate frequency and length of prey pursuit events while the remaining rows of bars highlight various features of the seafloor. The length of each bar shows how long the bird foraged over the respective feature.

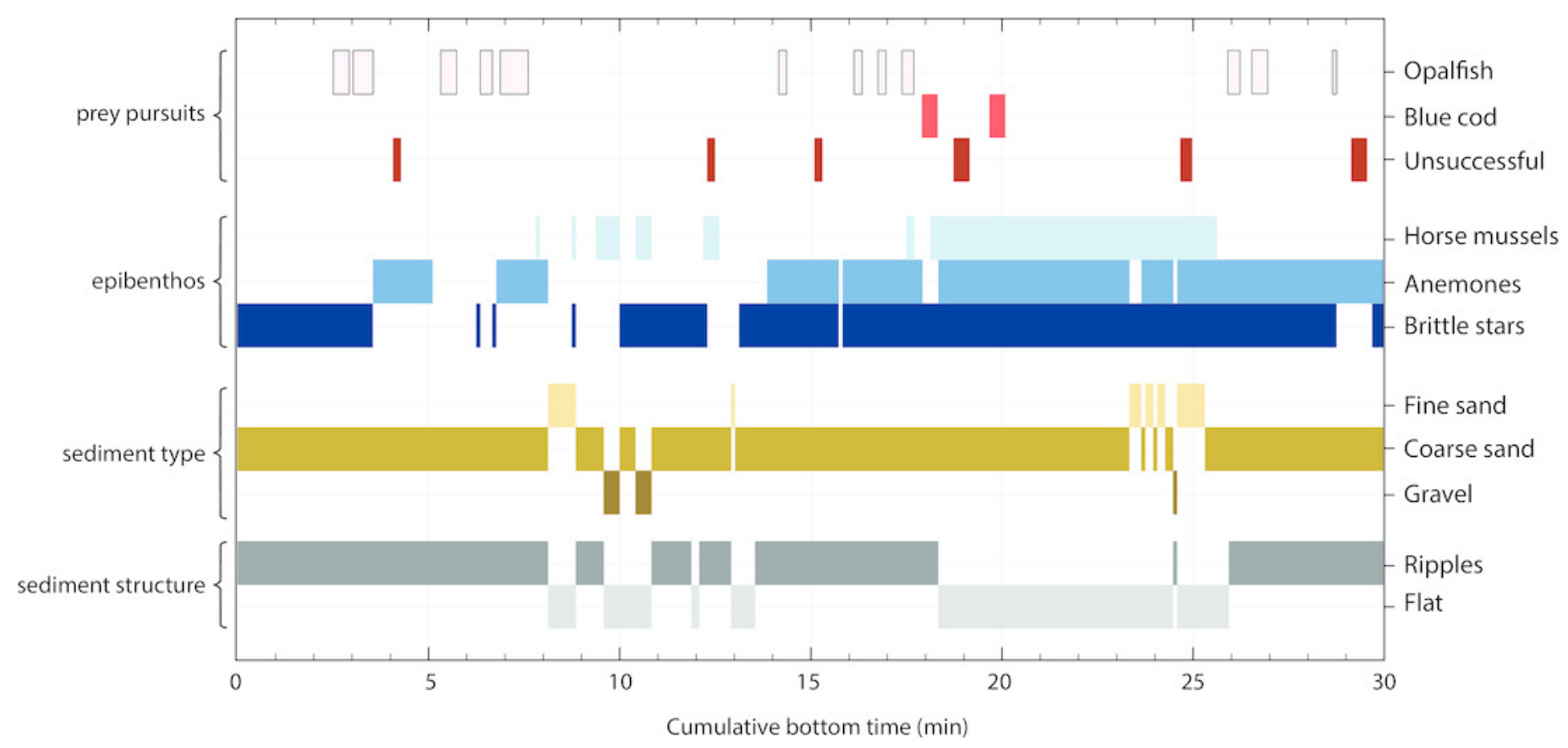




\section{Figure 4}

Flipper movements in a yellow-eyed penguin during the descent, bottom and ascent phases of 12 randomly chosen benthic dives.

Graphs in the upper row depict changes in flipper beat frequencies while the lower row consists of graphs showing flipper amplitude (i.e. maximum angle). Red lines indicate regression of the corresponding data (see Results for details). Note that $\mathrm{x}$-axis shows relative durations of the dive phases to account for dive dependent time variations. 


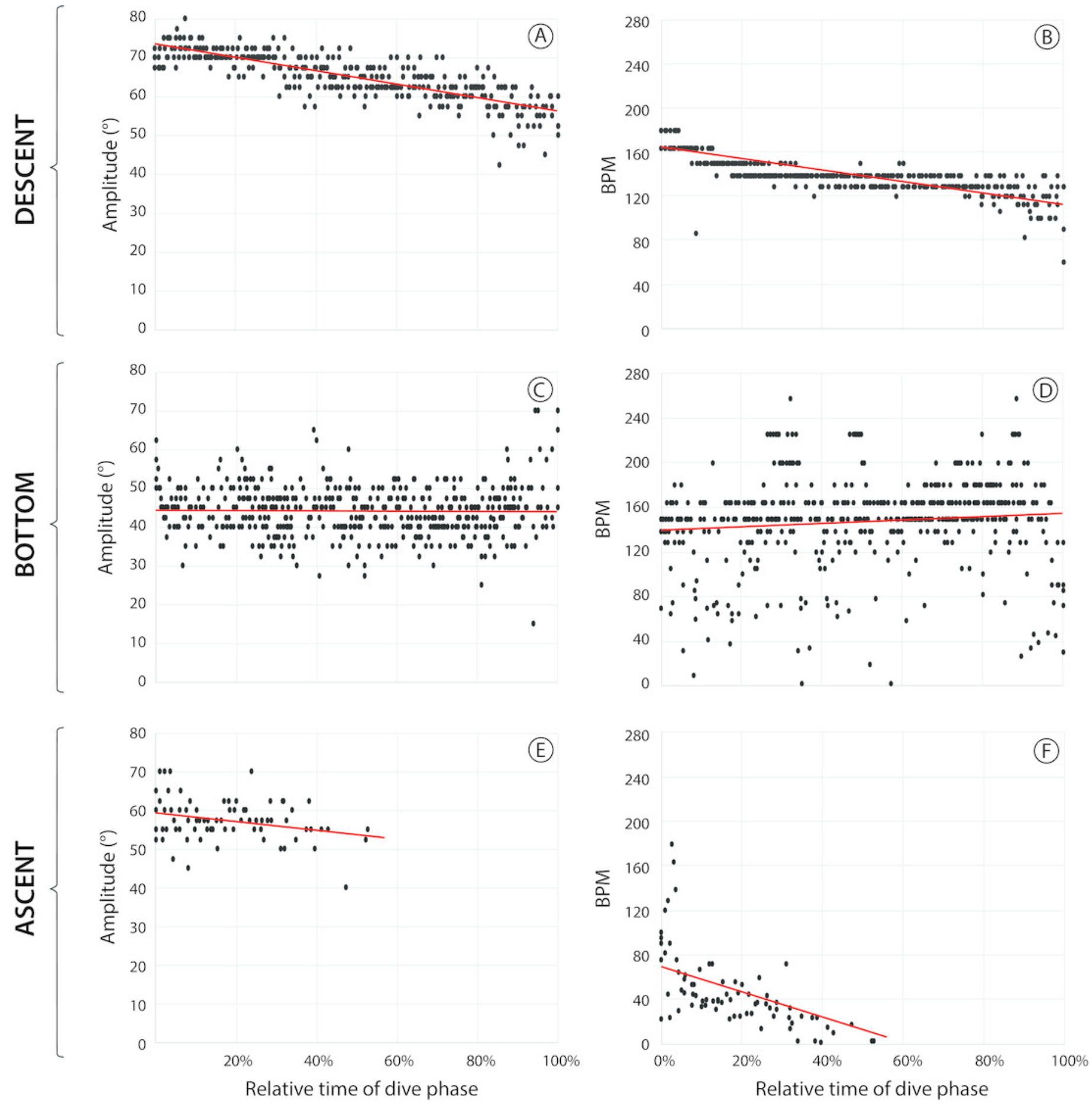


Figure 5

Increasing duration of breathing intervals $(n=193)$ during the surface period after 12 randomly selected dives performed by a yellow-eyed penguin.

Note that the $\mathrm{x}$-axis shows relative time to account for varying surface period durations. Red line indicates regression of data (see Results for statistical analysis).

1.8

1.6

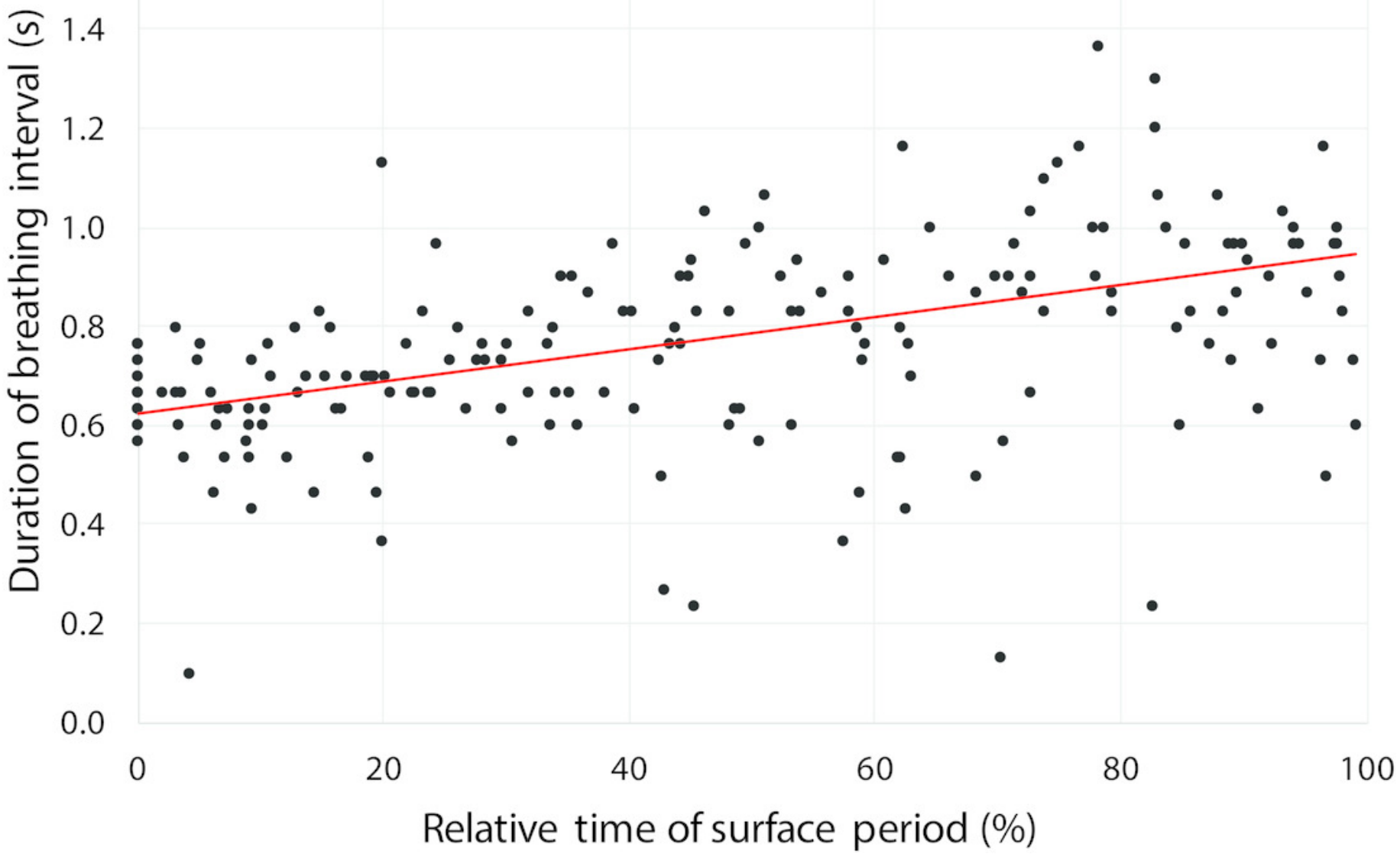

